\title{
Os lugares da viola no Vale do Paraíba (SP)
}

\author{
JOSÉ ROGÉRIO LOPES \\ Doutor em Ciências Sociais \\ Professor da Unisinos. \\ jrlopes@unisinos.br
}

ANDRÉ LUIZ DA SILVA

Doutorando em Ciências Sociais - PUC-SP

Professor da Universidade de Taubaté

interiworld@gmail.com

\begin{abstract}
Resumo O texto é um ensaio que tem por base pesquisa etnográfica realizada pelos autores e discute a importância da viola caipira para o estabelecimento de formações culturais em torno de um modo atual de sociabilidade característico da região do Vale do Paraíba (SP), os lugares de encontros de violeiros. Trata-se de apontar para a configuração de espaços apropriados de trocas musicais, em algumas cidades da região, onde os violeiros trocam experiências, difundem suas composições, atualizam seus repertórios, ou realizam 'disputas' musicais amigáveis em torno de temas característicos da música caipira e da sertaneja. Nesses encontros, formam-se laços de sociabilidade e de reconhecimento entre os sujeitos, que legitimam um modo de criação musical regional, que pode institucionalizar-se segundo os objetivos formais ou informais que os orientam.
\end{abstract}

Palavras-chave: violeiros; música caipira; sociabilidade; Vale do Paraíba.

para os violeiros:

"Não dá pé, não tem pé nem cabeça, não tem ninguém que mereça, não tem coração que esqueça, não tem jeito mesmo, não tem dó no peito, não tem nem talvez defeito, o que você me fez?"

Geraldo Azevedo

\section{Tirando o som (ou afinando as cordas)}

$\mathrm{O}$

S lugares da viola na região do Vale do Paraíba Paulista são vários, das festas de bairro, na roça, passando pelos bares de periferia dos centros urbanos, aos shows em praças, mercados, estações de rádios, centros culturais e salas de concerto. No entanto, os lugares físicos, como espaços concretos, são importantes somente por permitirem localizações àqueles que gostam de tocar ou ouvir o 
som da viola. Qualquer pessoa pode acessar uma diversidade de sítios na internet que os identificam ou relacionam ${ }^{1}$. Aqui, devemos reconhecer uma outra ordem de orientações, presentes nesses lugares todos. Trata-se de perceber que o verdadeiro lugar da viola é o da sociabilidade, nessa região marcada por um passado de formação caipira, que deixou incrustado na memória das pessoas um desejo particular de encontrar o outro, embalado pelas histórias dos lugares e dos acontecimentos que partilham, ou partilharam, contados como música.

José de Souza Martins (1975), em um texto já clássico, intitulado "Música sertaneja: a dissimulação na linguagem dos humilhados" (publicado anteriormente ao ano citado com o sugestivo título de "Viola quebrada"), já havia afirmado que a música caipira

[...] se caracteriza estritamente por seu valor de utilidade, enquanto meio necessário para efetivação de certas relações sociais essenciais ao ciclo do cotidiano do caipira. [...] Sem a música essas relações não poderiam ocorrer ou seriam dificultadas, acentuando a crise da sociabilidade mínima dos bairros rurais, como aliás se observa naqueles que estão em desagregação (Martins, 1975, p. 112).

A viola caipira, nesse sentido, é um instrumento valioso para os sujeitos que viveram as transformações sociais, econômicas e culturais ocorridas na região, nas últimas cinco décadas, sobretudo com a migração dos sujeitos rurais que foram para os centros urbanos da região, como São José dos Campos, Taubaté, Pindamonhangaba, Guaratinguetá e Cruzeiro.

A mudança do 'rosto' da região nesse período, de rural para predominantemente urbano e caracterizado pelo desenvolvimento tecnológico, parecia confirmar o enunciado de Octávio Ianni (1988), que afirmava na década de 1980 que o caboclo dos nossos amores estava se transformando em lúmpen proletariado nas cidades industriais. No entanto, em torno das manifestações propiciadas pelo uso da viola, entre outros motivos, formaram-se redes de sujeitos migrantes que trocam regularmente experiências e histórias, fortalecendo laços de parentesco, compadrio e amizades, nos novos contextos (Lopes, 1995).

As duas últimas gerações de migrantes, especialmente, têm fomentado um grupo de novos violeiros e de público para a música caipira, que agora começa a apresentar seus resultados, com a difusão progressiva que a viola vem alcançando no meio musical urbano da região e do país. E se essa difusão ficou obscurecida algum tempo é menos por causa da qualidade musical da própria viola e da música caipira, e mais por conta da idéia de 'progresso' que a região e o país viveram nessas últimas décadas, que isolou a figura do caipira, e de suas manifestações culturais, como símbolos de uma tradição que resiste às inovações (Lopes, 2005).

Porém, como afirmou Noel Andrade (violeiro urbano da nova geração regional) na entrevista que forneceu à nossa pesquisa:

a viola não parou no tempo, mas ficou encubado um tempo esse negócio da viola e ela ficou preservada nas mãos dos Foliões, esses violeiros muito simples, esse pessoal que canta a terra, as coisas que lê, vê, que ele ouve - informação oral de todas as maneiras. Tanto história, técnicas que são passadas na tradição oral, esse povo joga na música ${ }^{2}$.

Essa nova geração de violeiros mantém uma ligação e uma identificação intensa com o universo caipira, que resulta em uma combinação de preservação e mudanças na própria música caipira ${ }^{3}$, mostrando que a diversidade possível de ser extraída da viola ainda não foi explorada totalmente. No entanto, os sinais dessa diversidade são percebidos pelo violeiro, como nos conta o próprio Noel:

Eu conheço esse espírito [...] conheço esse universo, mas eu não fiquei lá na roça, do dia em que nasci até ontem, eu morei na cidade, eu estudei, eu estou aqui. Eu conheci outras coisas, ouvi rock, muito rock, muita coisa, eu ouvi música clássica, música brega, eu escutava com os meus amigos [...] Então, eu não consigo fazer uma música tão pura, de raiz, como esse violeiro que está lá na roça, que vive lá. Aquela mão que preservou a viola não é a minha, mas tem da mão dele na minha. Só que a minha já não é a dele mais.

Vê-se, assim, que as traduções culturais dos violeiros urbanos resultam em composições musicais que inovam e sofisticam o uso da viola caipira, sem perder o fundo cultural e religioso que sustenta a sonoridade do instrumento. Traduções culturais que já inspiraram análises acadêmicas, como na bonita dissertação de Souza (2002).

1 Uma busca no Google, ou outra ferramenta similar, relacionando as palavras viola caipira, música caipira, violeiros e região do Vale do Paraíba, é procedimento suficiente para localizar esses sítios e lugares.

2 Alguns procedimentos e estratégias que os sujeitos populares operaram em torno da guarda desse instrumento podem ser percebidos nos estudos sobre rituais devocionais populares, como em Brandão (1981).

3 Como exemplo, o Grupo Paranga, de São Luis do Paraitinga (município localizado na Serra do Mar, entre Taubaté e Ubatuba) foi um dos primeiros a mesclar a tradição musical da região com novos ritmos, criando um estilo musical que fez sucesso na década de 1980 , depois da participação do grupo nos festivais da TV Globo. 
E lembrando Stuart Hall (2005, p. 103), essas traduções são elaboradas “[...] por gente que viaja, mesmo quando permanece em suas casas ou escritórios". Nesse sentido, é próprio afirmar que as traduções podem até ser locais, mas os criadores culturais que as elaboram são "sujeitos em trânsito" pelos processos da globalização ${ }^{4}$, como o "homem em trânsito" consumidor de cultura, descrito por Toffler (1965, p. 50).

Daí, que a música caipira, acompanhada da viola tocada por esses sujeitos, torna-se um objeto adequado para entender a idéia elaborada por Raymond Williams (1979) de que a tradição, ao confrontar-se com a cultura hegemônica, torna-se superestrutura, ou, em linguagem simples, permanece presente na memória das pessoas, ou nas suas próprias vidas, mais como abstração que como realidade, porque esta não é mais como foi, no passado.

Como cantam Cacique e Pajé, na música Pó de Mico: "Minha rima vem de cima, / nos meus versos logo aplico,/ com a minha viola no peito,/ não dou voltas nem tropico./ Prá furar barra da inveja,/ meu pagode é um maçarico,/ prá fazer dançar miudinho,/ minha viola é um pó de mico" 5 .

Nas mãos dos violeiros, ou dos 'tocadores de viola' - como se denomina o músico Galvão Frade, de São Luis do Paraitinga - na roça e nas cidades, nos bailes ou nos bares, a viola puxa a memória e redefine o lugar, atualizando os motivos de vida das pessoas. Ela também incita a sociabilidade, contra inveja, ruindade, doença, ou outra coisa qualquer que atrapalhe as relações comunitárias fundadas em um ideal de solidariedade vicinal, de participação e companheirismo, enfim, de fortalecimento dos nós e laços traçados com o outro, na vida afora.

Essa é a marca da identificação do sujeito valeparaibano com a viola. Nela, passado e presente complementam-se para fazer dos domingos à noite, na praça do Fórum, no centro de Taubaté, ou dos Manifestos Culturais no Mercado Municipal de São Luis do Paraitinga, uma arena para a música Saudade de Minha Terra" (de Belmonte e Goiá), cantada por centenas de sujeitos como se fosse um hino (aliás, sêo Nelson Alvarenga, violeiro e radialista de São Luis do Paraitinga, afirma que a música é um hino mesmo).

E se a saudade do passado torna a música melancólica, a atualidade da viola caipira torna o lugar em que ela é tocada um lugar próprio do encontro das pessoas. E é por aí que continuamos.

\section{Toadas (ou tocando a moda)}

Os lugares de encontro propiciados pela viola e pela música caipiras são, antes de tudo, lugares onde os sujeitos realizam apropriações, por identificação, como afirma Martins (1975, p. 113):

Embora o cantador de uma moda possa indicá-lo (às vezes eles mesmo), o modo como ela é construída envolve um saber que tem em conta a reação e a avaliação das pessoas às quais o violeiro se liga no emprego de sua arte. Cantar (e contar) um acontecimento depende, basicamente de que se faça de conformidade com as expectativas e concepções dos circunstantes. Neste plano, o compositor apenas traduz em composição verbal e musical as concepções coletivas.

O mais tradicional desses lugares foi a religião, sem dúvida, esse 'lugar' formador dos sujeitos que preservaram a viola nos rituais populares das Folias de Reis, dos Reisados, e também nos encantados ritmos profanos que embalavam os interstícios desses rituais, como a Catira, a Cana Verde, e outros cantos e danças desse pessoal. Entretanto, o mais importante, para o que hoje importa reconhecer aqui, talvez seja o rádio. E o leitor pode perguntar-se: Ué! E rádio lá é lugar??? É!!!

O rádio é um lugar e um instrumento do lugar, pois capta as ondas sonoras da intencionalidade dos sujeitos que cantam, e permite que o sujeito ouvinte as atualize para si, onde esteja. De novo, a música Pó de Mico, de Cacique e Pajé, nos ajuda a compreender essa intencionalidade: "Na onda de uma estação, / pelo rádio eu comunico./ Pro meu povo sertanejo,/ modas boas eu dedico".

Na região do Vale do Paraíba, são muitos aqueles que lembram e nos relataram já ter acordado, nos primeiros raios de sol da manhã, com o pai ligando o rádio nos programas de música caipira, ou sertaneja, ouvindo chamadas do tipo: "Acorda, dona Maria, que o sol já raia e a manhã já brilha. Acorda, sêo José, e vai fazer o café". Sem contar o mistério que rondava a imaginação das crianças que descobriram o próprio rádio, como nos descreveu Benê Freitas, apresentador do programa "Manhã Sertaneja”, na Rádio Difusora de Taubaté:

[...] era o famoso rádio 'rabo quente', ainda era cobertura de plástico, invólucro de plástico - aquele Philips

4 Isso permite pressupor que as traduções elaboradas sobre as relações entre culturas locais e a cultura global (Featherstone, 1994) têm gerado conflitos, ou o que vimos denominando de fricções interculturais. O que ocorre nas fricções interculturais, nos interstícios da globalização, é uma crescente mediatização estratégica ou tática das formas e conteúdos identitários e de criação cultural que se impõem aos sujeitos e grupos das sociedades "periféricas", desde a tendência à homogeneização cultural da globalização.

5 Pó de Mico: autoria de Demério de Oliveira, Cecílio Bernardes da Silva e Cacique. In: CD Brasil 500 anos, de Cacique e Pagé. Ed. Allegretto. 
antigo - eu lembro que até a capa dele era meio quebrada. De onde meu pai trouxe aquilo lá, eu não sei. Sei que tinha que apertar o fio para poder funcionar, era o 'rabo quente'.

Essa memória é que permite que o rádio ainda seja um meio de comunicação importante para esses sujeitos. Alguns deles, sobretudo nas periferias das cidades da região, ainda possuem o mesmo rádio - com aquela antena de fio esticado em cima do telhado, ou um Motorádio portátil à pilha - de trinta anos atrás, como sêo Rafael, da dupla Daniel e Rafael, de Guaratinguetá. Isso também é o que explica que os programas de rádio mais duradouros da região fossem, ou sejam, os de música sertaneja, como o programa "Sítio do Coquinho", do radialista Coquinho, de São José dos Campos; do Simãozinho, também em São José dos Campos; do Benê Freitas, em Taubaté; do Hélio Moreira, em Lorena; do Praianinho, em Aparecida, ou do sêo Nelson Alvarenga, em São Luis do Paraitinga. Isso também é o que explica a presença de alguns desses sujeitos nesse ensaio sobre violeiros. Eles são os agentes difusores de muitas dessas intencionalidades musicais, no rádio e fora dele, em festas de bairro, ou nos atuais clubes, casas e associações de violeiros que se espalham pela região.

O rádio também é um lugar de reconhecimento. Mais propriamente, a estação de rádio ou o programa de rádio. Já que a maioria dos violeiros da região não consegue gravar um $\mathrm{CD}$, ou não conseguiu gravar um Disco (os antigos discos de vinil, para quem não se lembra mais), tocar ou 'cantar na rádio' é algo que sempre surgiu como estratégia de legitimação da sua qualidade musical, nas entrevistas dos violeiros. Faz parte do currículo desses sujeitos ter tocado na Rádio Aparecida (Aparecida), nas Rádios Cacique ou Difusora (Taubaté), na Rádio Piratininga (São José dos Campos). E em quantas mais rádios, melhor! Essa é uma forma de reconhecimento que os aproxima de seus ídolos, tão citados nas entrevistas: Tião Carreiro e Pardinho, Tonico e Tinoco, Zé Carreiro, Carreirinho, Zilo e Zalo, Cacique e Pajé, Cascatinha e Inhana, Vieira e Vieirinha, Milionário e José Rico, Geno e Geninho, Zico e Zeca, Léo Canhoto e Robertinho, Duduca e Dalvan, Lio e Léo, Belmonte e Amaraí, Paixão e Paixola, e os compositores, todo mundo já ouviu Coração de Luto, de Teixeirinha, ou as músicas de Anacleto Rosa, José Fortuna, Goiá, Moacir dos Santos e Lourival dos Santos, além de Elpídio dos Santos, clássico regional do Vale do Paraíba, que tantas músicas compôs para os filmes de Mazzaropi e outros músicos desse país.

E como os lugares de encontros também são lugares de trocas, talvez isso explique porque tantos violeiros reúnem-se todos os domingos nos bares em torno das Feiras da Barganha, em Taubaté, ou no Bairro de Santana, em São José dos Campos; no mercado de Pindamonhangaba; nos bares próximos das barracas que oferecem mercadorias aos Romeiros, em Aparecida, ou ainda, quinzenalmente, no Mercado Municipal de Lorena, comandados por Hélio Moreira e João Mateiro, além de outros locais similares, em quase todas as cidades do Vale do Paraíba. Esses são lugares tradicionais dos migrantes que, desde antes de mudarem para as cidades, construíram referências sobre a regularidade das trocas mercantis dos excedentes que eles e seus pais produziam na zona rural: feijão, milho e cana - lavouras tradicionais na região - ou criações como frangos e porcos, além de derivados de uns e de outros como a pamonha, o curau, a rapadura, a cachaça, ou ovos e queijos.

Nesse contexto, a viola tem outros sabores. Ela confunde-se com os cheiros da fritura de torresmos e pastéis, dos 'paieiros' (cigarros de palha) e dos fumos de rolo, do café tropeiro, nas mãos daqueles que, entre um acorde e outro, sorvem um gole de Mato Dentro ou outra cachaça de alambique. Ah! e como a cachaça acompanha a viola, nesses lugares. Chega até a embriagar de um jeito, que você não sabe qual delas dá mais tontura - porque a viola também dá. Confessamos que nós mesmos, em um desses encontros dominicais - no Bar do Cipó, perto da Feira da Barganha, em Taubaté - ouvimos tantas modas e tomamos tantas cachaças, que não sabíamos mais se era o violeiro que tocava a viola, ou a viola que tocava o violeiro. E como quaisquer antropólogos que se prezam, foi nesse dia que resolvemos tomar uma resolução: ou a pesquisa ou os derivados da pesquisa!

Em torno dos mercados também se disputam melodias e letras, ao som de Calangos (um desafio entre cantadores, baseado em improvisos seqüenciados numa série de rimas predeterminadas por um dos participantes) ou de desafios de duplas - daquelas em que uma dupla chama uma música para a outra cantar, até que uma saia 'vencedora' - que lembram muito as antigas barganhas que se faziam entre objetos variados, nas feiras da região. Trata-se de um jogo de reconhecimentos entre os violeiros, em que se afirma uma condição de legitimidade e de maestria no trato com o instrumento.

Esses e tantos outros encontros mais descontraídos entre os pares parecem compor o cenário de um ensaio geral para os sujeitos que, em outras situações, precisam estar afinados para tocar. Pensamos que esse é o sentido de tais encontros, marcados pela superficialidade característica da sociabilidade (Simmel, 1983). Nesses lugares e encontros, os violeiros afinam a mão e a viola para que, nas situações "sérias", estejam preparados. Sêo Nelson de Alvarenga, de São Luis do Paraitinga, confirma a idéia, ao narrar o seguinte acontecimento: 
[...] teve um festival da pilha Eveready, foi promovido da rádio Record. Tinha uns caras famosos de lá, foi no Taubaté Country Club. Era o Carlito Martins o locutor, chegou a ouvir o Carlito Martins, da Record? Mas, fomos infelizes. Depois, ele lamentou, coçou a cabeça e disse - Olha, essa música era a música [...] a melhor música do festival, a melhor letra do festival. Erramos na hora de cantar. Porque aquele tempo não era que nem hoje, que o cara chega no microfone, vai afinar instrumento. Não! O locutor anunciava a música e você chegava e cantava, nem cumprimentar não cumprimentava, era no estouro mesmo. Então, nós chegamos, quando foi no terceiro verso, que a música tinha quatro versos, no terceiro verso deu uma falhada, um saiu meio na anca do outro, e pronto. E talvez nós tivéssemos ganhado.

Está aí elaborada a passagem dos lugares: daquele do encontro descontraído para o da exibição, do ensaio para o 'espetáculo', do reconhecimento para a competição. Essas oposições são sempre presentes na sina dos violeiros populares que buscam aproximar-se do reconhecimento: ao exibir o seu talento, competir com o talento do outro. Daí que os festivais são lugares constantes na experiência dos violeiros, em que a 'magia' de um ou de outro pode ser explorada, decodificada; o toque do outro na viola pode ser analisado e apropriado, posteriormente. Aliás, uma referência que podemos elaborar como observadores recentes dos violeiros é essa: um violeiro que vê e ouve outro violeiro tocar olha os seus movimentos na viola, e não o próprio violeiro.

A alma do som está na viola, não no violeiro embora respeito seja bom ao homem! Essa idéia é que anima tantas superstições em torno do aprendizado da viola caipira, fazendo com que ela seja também um lugar de crenças: enrolar uma cobra entre os dedos, pegar em uma viola tocada pelo 'demo', colocar guizo de cobra no interior da viola, pendurar mandingas no braço da viola, imagens religiosas, entre outros sinais de que o instrumento é do diabo, mesmo! Para proteção, ou para danar de vez, essas crenças são sempre referências encontradas e reforçadas por quem deseja ser um bom violeiro (Corrêa, 1983, 2000).

E que lugar é esse, de uma viola que se difunde no Brasil pela evangelização jesuíta e se define como lugar de Deus, como contam Oliveira (2000) e Souza (2002), mas se insinua no imaginário popular como coisa diabólica, como arte?

Trata-se do lugar da ambigüidade, da diversidade, da pluralidade e de outras tantas idades encarnadas na viola caipira e na prática dos violeiros da região, caipiras ou não.

O que ajuda a explicar essa ambigüidade, talvez, seja o fato de que, na região do Vale do Paraíba, até o final do período imperial, os sujeitos de referência para a difusão da viola não foram os jesuítas (raros por aqui), mas os tropeiros, que provavelmente aprenderam a tocar o instrumento na interação com aqueles missionários. Dessa forma, ao caráter lúdico religioso do uso do instrumento, definido na estratégia de evangelização dos jesuítas, soma-se o caráter narrativo próprio dos tropeiros, sujeitos dados a muitas viagens e causos, envolvendo experiências com o inusitado. Isso explicaria a tradição da 'moda de viola' como expressão musical dos registros culturais da sociabilidade caipira (a lida no campo) e sua ênfase moral, hesitante entre o bem e o mal, de herança evangelizadora (Martins, 1975).

A denominação de 'moda de viola' também está sujeita aos registros próprios do movimento histórico do instrumento: no contexto popular, as músicas cantadas e tocadas 'à moda de viola' representavam um tipo de musicalidade próprio, como nos salões, a viola era um instrumento utilizado para tocar Modinhas (Azevedo, 1943; Oliveira, 2000). Daí que é mais apropriado pensar na denominação dada à música caipira, ou sertaneja, como um registro que toma forma em um processo de circularidade de influências entre domínios distintos da experiência cultural brasileira, mas em constante interação. E nessa interação, fundem-se os registros de ambos os lados (Nepomuceno, 1999).

E como as adjetivações dos lugares da viola mudam e "as tradições são inventadas", como já escreveu Eric Hobsbawm (1997), surgem ritos de passagem como o Batismo de Violeiros, criado pelo sêo Zé Mira e realizado no Rancho do Tropeiro, no distrito de Eugênio de Melo, em São José dos Campos. Nesse batismo, violas e violeiros passam por ritos de iniciação, que incluem compromissos com a causa da música caipira, ou 'música de raiz', como alguns preferem. E tem algo interessante nessa adjetivação, na idéia de que, como a planta, a música caipira também tem que ser cultivada, mas seu fruto é como o da batata, ou o da mandioca: tem que ser escavado.

E o que falar, então, das 'casas de violeiros' que têm se espalhado pela região, desses lugares que, como o próprio nome sugere, segundo Tonino Bettanini (1982), remetem à unidade espacial do meio rural - a casa - em contraposição à unidade espacial do meio urbano, que é a propriedade. Ao passo que, na primeira, os motivos do trabalho agrícola fazem convergir contornos naturalmente coletivos aos encontros das pessoas, na segunda prevalece a privacidade e um modelo de intimidade que isola os sujeitos do contato com o outro. Daí que, nos encontros semanais que se realizam nesses lugares, nada se cobra para entrar e participar.

Essas 'casas', assim como os lugares que servem de encontro para os ensaios das Orquestras de Violas - e, por que não, as próprias Orquestras de Violas? - são lugares onde se elaboram traduções e negociações cul- 
turais, onde a tradição negocia com movimentos emergentes, e os velhos 'caipiras' ensinam aos jovens urbanos muito mais do que a tocar viola: ensinam a reencantar a viola, reencontrando a cultura e fazendo dela uma crença. Quando assistimos um violeiro aprendiz chamado Paulo Tarasso tocando a Bachiana para Viola, de Fernando Deghi (jovem violeiro urbano paulista, de formação erudita), em uma violinha tonante, no encontro dominical de duplas caipiras em Guaratinguetá, cremos ver confirmar-se essa predisposição a uma circularidade de influências entre o tradicional e o emergente.

E o que dizer, então, da difusão crescente da viola entre jovens violeiros que se apresentam em bares e points alternativos das cidades da região, especialmente nas serranas e turísticas? São violeiros em cidades que também são caipiras: São Bento do Sapucaí, São Luis do Paraitinga, São José do Barreiro, Santo Antônio do Pinhal, Santa Branca e Paraibuna. Da Serra do Mar, nas margens do Rio Paraitinga, à da Mantiqueira, no município de São Francisco Xavier, a moda é violeira, nas mãos desses diversos sujeitos que assumem a Viola como sobrenome - e o nome, aprende-se cedo em Antropologia, também identifica um lugar: Pereira, Braz, Zé, Bidu, Paulo, Toninho, Luis, Paulinho da Viola. A seguir no encalço dos textos de Tinhorão (1990), Sant'Anna (2000) e Souza (2002), essa deve ser uma das famílias mais antigas do nosso país e, talvez, uma das mais numerosas.

E se há um parentesco entre esses violeiros, mesmo que virtual, os sítios que eles elaboram e colocam na internet confirmam uma característica familiar: o lugar desses sujeitos é no planeta Música, como nos disse o Negão, do Grupo Paranga: "Um lugar que não tem mundo, num mundo que não tem lugar”. Nesses sítios, a música confunde-se com a história dos sujeitos a um ponto que, ao aparecer uma fotografia, a música surge também espontaneamente. As imagens que se sucedem parecem desvendar mistérios contidos nos acordes das violas, como imagens melodias - imagens melódicas!

E, por fim, como lugares são centros aos quais atribuímos valores e onde são satisfeitas nossas necessidades, como escreveu Yi-Fu Tuan (1983), cabe ressaltar aqui o papel dos centros culturais da região. Desde a Fundação Cultural Cassiano Ricardo, em São José dos Campos (que abriga a Orquestra de Violas), passando pelo SESC de Taubaté (que realiza o Rancho da Viola), até outros lugares similares espalhados pelas cidades do Vale do Paraíba, esses centros têm sido verdadeiros pontos de encontro e de difusão da cultura local e caipira. Mais que isso, eles têm confirmado um "campo de possibilidades" (Velho, 1994) e de pluralidade representado pela viola, como a segunda voz das duplas caipiras, que, mais que repetir o que a primeira voz canta, sobretudo reforça o enunciado contido na canção, tornando-o coletivo e ampliado.

\section{Arremate (ou encerrando a apresentação)}

O lugar que fecha este texto e o resumo é o mais percebido em toda a pesquisa que realizamos, é o lugar particular da viola, para cada violeiro: um oratório musical. Lugar simbólico que a viola representa para os violeiros e que cada um atualiza a sua maneira, mas que constitui um fundo comum herdado dos tempos da colonização, em que a viola é trazida ao Brasil, passando a ser utilizada como um instrumento para a difusão do que viria a configurar a cultura católica brasileira, no universo da cultura popular e na região mais interiorana do 'Brasil caipira'.

Seja nas casas de cada um, ou nas 'casas' coletivas, a viola sempre recebe um tratamento especial. Ela é a 'companheira', a 'amante', 'é da família', como dizem os violeiros, cabendo a ela um lugar particular, reservado e preservado menos pelo seu valor material, e mais, pelo seu valor sentimental. Ela pode ser uma Del Vecchio Tonante de série como a do Pedro Sertanejo, de Taubaté, uma Yamaha como a do Negão, de Lagoinha, ou uma viola de luthier, como as produzidas por Régis Bonilha, de Jacareí, mas vai ser sempre a viola. E se há mais de uma, elas são sempre colocadas juntas, como se pudessem trocar as propriedades que carregam, como se uma pudesse capturar a qualidade da outra, em uma contigüidade musical.

A viola, na casa ou na mão do violeiro, é como uma imagem de santo, algo que representa muito mais que o objeto que ela é. Assim como a imagem de santo simboliza virtudes e exemplos, a viola simboliza valores culturais que expressam raízes profundas da experiência dos sujeitos que a tocam. Talvez, por isso, os violeiros tenham tanto ciúme das violas que possuem, ao ponto em que, nas mãos de outros, elas desafinem.

A viola, enfim, é tudo isso e mais um pouco, e seus lugares não cabem neste texto, pelo simples motivo de que nós a descrevemos, mas não a escrevemos; de que seu verdadeiro lugar é no peito e nas mãos do violeiro e nos ouvidos de quem a aprecia, e não, no teclado do computador de quem a estuda.

Entretanto, caso tudo que escrevemos até aqui serviu para algo que seja, que seja para estimular o leitor a ouvir mais a viola caipira, não importando o lugar, "na rua, na chuva, na fazenda ou numa casinha de sapê", como cantou Hildon, ou na interpretação de um Tião Carreiro, de sêo Zé Mira, de sêo Renô Martins, de Almir Sater, Pereira da Viola (quem não ouviu Fuxico, não conhece a melodia violeira do amor!), Fernando Deghi, Paulo Freire, Roberto Corrêa, Ivan Vilela, e outros tantos violeiros menos conhecidos e aqui pesquisados. 
Assim como os caipiras colonizaram esse país, preparando-o para o uso histórico que dele fizemos (Brandão, 1983), esses violeiros, antigos e novos, arriscam-se na música para arar o terreno que faz a transição das nossas sensibilidades tradicionais e inovadoras. E quantas combinações e inovações ainda podem emergir deles!

\section{Referências}

AZEVEDO, L. H. C. A moda de viola. Cultura Política, Rio de Janeiro, v. 3, n. 32, p. 181-184, set. 1943.

BETTANini, Tonino. Espaço e Ciências Humanas. Rio de Janeiro: Paz e Terra, 1982.

BRANDÃO, Carlos Rodrigues. Sacerdotes de viola. Petrópolis: Vozes, 1981.

Os caipiras de São Paulo. São Paulo: Brasi-

liense, 1983.

CORRÊA, Roberto. Viola Caipira. Brasília: Editora $\mathrm{Mu}-$ simed, 1983.

Autor, 2000

$A$ arte de pontear viola. Brasília: Edição do

FEATHERSTONE, Mike (Org.). Cultura global. Nacionalismo, globalização e modernidade. Petrópolis: Vozes, 1994.

FERRETE, J. L. Capitão Furtado: viola caipira ou sertaneja? Rio de Janeiro: Funarte, 1985.

HALL, Stuart. A identidade cultural na pós-modernidade. 10. ed. Rio de Janeiro: DP\&A, 2005.

HOBSBAWM, Eric J.; RANGER, Terence (Orgs.). A invenção das tradições. 2.ed. Rio de Janeiro: Paz e Terra, 1997. IANNI, Octávio. Cultura do povo e autoritarismo das elites. In: VALLE, Edênio; QUEIRÓZ, José J. (Orgs.) A cultura do povo. 4. ed. São Paulo: EDUC, 1988, p. 134-140.

LOPES, José Rogério. A cultura como crença: estratégias modernas de reprodução da vida popular. São Paulo: Robe/ Cabral, 1995.

Industrialização e mudanças culturais no Vale do Paraíba, São Paulo. In: CHAMON, Edna M. Q. O; SOUZA, Cidoval M. (Orgs.). Estudos interdisciplinares em Ciências sociais. Taubaté: Cabral Universitária, 2005, p. 193-218.

MARTINS, José de Souza. Capitalismo e tradicionalismo. São Paulo: Livraria Pioneira Editora, 1975.

NEPOMUCENO, Rosa. Música Caipira: da roça ao rodeio. São Paulo: Editora 34, 1999.

OLIVEIRA, Ernesto Veiga. Instrumentos musicais populares portugueses. Lisboa: Fundação Calouste Gulbenkian/Museu Nacional de Etnologia, 2000.

SANT'ANNA, Romildo. A moda é viola. São Paulo: Arte e Ciência, 2000.

SIMMEL, Georg. Sociabilidade: um exemplo de sociologia pura ou formal. In: MORAES Fo, Evaristo (Org.). Simmel (Col. Grandes Cientistas Sociais). São Paulo: Ática, 1983, p. 165-181.

SOUZA, Andréa Carneiro de. Viola - do sertão para as salas de concerto: a visão de quatro violeiros. Dissertação (Mestrado, Curso de Pós-Graduação em Música) - UNIRIO, Rio de Janeiro, 2002.

TINHORÃO, José Ramos. História social da música popular brasileira. Lisboa: Editorial Caminho, 1990.

TOFFLER, Alvin. O povo e a cultura. Rio de Janeiro: Lidador, 1965.

TUAN, Yi-fu. Espaço e lugar: a perspectiva da experiência. São Paulo: Difel, 1983.

VELHO, Gilberto. Projeto e Metamorfose: antropologia das sociedades complexas. Rio de Janeiro: Zahar Editores, 1994.

WILLIAMS, Raymond. Marxismo e literatura. Rio de Janeiro: Zahar, 1979. 


\section{Los Lugares de la Guitarra en el Vale del Paraíba (SP)}

\section{Resumen}

El texto es un ensayo escrito a partir de la investigación etnográfica realizada por los autores y discute la importancia de la guitarra 'caipira' para el establecimiento de formaciones culturales en torno de un modo actual de sociabilidad característico en la región del Vale do Paraíba, estado de São Paulo, Brasil: los lugares de encuentros de los guitarreros. Se trata de apuntar hacia la configuración de espacios apropiados de intercambios musicales, en algunas ciudades de la región, donde los guitarristas intercambian experiencias, difunden sus composiciones, actualizan sus repertorios, o realizan 'disputas' musicales amigables en torno de temas característicos de la música 'caipira' y 'sertaneja. En esos encuentros, se forman lazos de sociabilidad y reconocimiento entre los sujetos, que legitiman un modo de creación musical regional, que puede institucionalizarse de acuerdo a los objetivos formales o informales que los orientan.

Palabras-clave: guitarreros; música 'caipira'; sociabilidad; Vale do Paraíba.

\section{The Places of Viola in the Paraíba Valley (SP)}

\section{Abstract}

This is an essay based on an ethnographic research done by the authors and it discusses the importance of viola caipira (a kind of folk guitar) for the establishment of cultural formations of present modes of sociability characteristic of the Paraiba Valley region (SP), where players meet. The paper aims at showing the configuration of appropriate spaces of musical exchange in some cities of the region, where the players exchange experiences, publish their compositions, update their repertories or perform friendly musical disputes around themes which are typical of caipira and sertaneja music. In these meetings, a network of sociability and mutual recognition is formed, thus legitimizing a mode of regional music creation which may become institutionalized according to the formal and informal objectives which guide them.

Key words: viola players; caipira music; sociability; Paraiba valley.

Data de recebimento do artigo: 30-04-2008

Data de aprovação do artigo: 28-08-2008 